\title{
Progressive Degeneration of Dopaminergic Neurons through TRP Channel-Induced Cell Death
}

\author{
Archana Nagarajan, ${ }^{1}$ Ye Ning, ${ }^{2}$ Kaja Reisner, ${ }^{1}$ Zafir Buraei, ${ }^{3}$ Jan Petter Larsen, ${ }^{2}$ Oliver Hobert, ${ }^{4 \star}$ and \\ Maria Doitsidou ${ }^{1,2,4 *}$ \\ ${ }^{1}$ Center for Organelle Research, University of Stavanger, 4036 Stavanger, Norway, ${ }^{2}$ Norwegian Center for Movement Disorders, Stavanger University \\ Hospital, 4011 Stavanger, Norway, ${ }^{3}$ Department of Biology and Health Sciences, Pace University, New York, New York 10038, and ${ }^{4}$ Department of \\ Biochemistry and Molecular Biophysics, Howard Hughes Medical Institute, Columbia University Medical Center, New York, New York 10032
}

Progressive neurodegenerative diseases are among the most frequently occurring aging-associated human pathologies. In a screen for Caenorhabditis elegans mutant animals that lack their normal complement of dopaminergic neurons, we identified two strains with progressive loss of dopaminergic neurons during postembryonic life. Through whole-genome sequencing we show that both strains harbor dominant (d), gain-of-function mutations in the Transient Receptor Potential (TRP) mechanosensory channel trp-4, a member of the invertebrate and vertebrate TRPN-type of the TRP family channels. Gain-of-function mutations in TRP channels have not been previously implicated in dopaminergic neuronal degeneration. We show that $t r p-4(d)$ induces cell death in dopamine neurons through a defined, calcium-related downstream pathway.

Key words: C. elegans; calcium; cell death; dopaminergic neurons; neurodegeneration; TRP channels

\section{Introduction}

In an ever-aging population, neurodegenerative disorders, characterized by progressive loss of structure or function in various neuronal cell types, are bound to increase. Although several genetic causes of neurodegenerative diseases have been discovered, for the majority of them the causes as well as the underlying molecular mechanisms remain elusive. Nevertheless, family histories and lessons from GWAS suggest a substantial contribution of still undiscovered genetic susceptibility factors to disease etiology (Lesage and Brice, 2009; Lill and Bertram, 2011). Studies using various animal models of neurodegenerative disease have collectively illuminated some aspects of the molecular pathology of such conditions (Harrington et al., 2010; Lee et al., 2012). In addition, these studies uncovered novel triggers of neuronal cell death, which resulted in the discovery of downstream molecular mechanisms contributing to the process (Driscoll and Chalfie,

Received Oct. 25, 2013; revised Feb. 13, 2014; accepted March 7, 2014.

Author contributions: O.H. and M.D. designed research; A.N., Y.N., K.R., and M.D. performed research; J.P.L. and 0.H. contributed unpublished reagents/analytic tools; A.N., Z.B., and M.D. analyzed data; A.N., O.H., and M.D. wrote the paper.

This work was funded by MJFF Rapid Response Innovation Awards to M.D. and 0.H., Marie Curie Fellowship to M.D. (IRG 276950), Fellesløftet-NFR (213957) to M.D., Helse Vest Fellowship (911724) to M.D., Helse Vest project Grant (911732) to M.D., Norwegian Parkinson's Associations Grant 2011 to M.D., the National Institutes of Health (R01NS050266 to 0.H.), and the Howard Hughes Medical Institute. We thank CGC for strains; Alex Boyanov, Jason Han, and Surinder Narula for technical assistance; Shawn Xu lab for kindly providing the Pdat-1::trp-4 plasmid; Dr. Jodi Maple Grødem and Tatiana Popovitchenko for comments on this manuscript.

${ }^{*} 0$.H. and M.D. contributed equally to this work.

The authors declare no competing financial interests.

Correspondence should be addressed to either of the following: Oliver Hobert, Department of Biochemistry and Molecular Biophysics, Howard Hughes Medical Institute, Columbia University Medical Center, New York, New York 10032, E-mail: or38@columbia.edu; or Maria Doitsidou, Center for Organelle Research, University of Stavanger, N-4036 Stavanger, Norway, E-mail: maria.doitsidou@uis.no.

DOI:10.1523/JNEUROSCI.4540-13.2014

Copyright $\odot 2014$ the authors $\quad 0270-6474 / 14 / 345738-09 \$ 15.00 / 0$
1991; Hong and Driscoll, 1994; Yoon et al., 2000; Kim et al., 2007; $\mathrm{Ni}$ et al., 2008). Thus, identifying new genetic causes of neuronal degeneration in model organisms can enhance our mechanistic insights into neurodegenerative diseases in humans.

Despite their differences, most major neurodegenerative diseases share several clinical, pathological, and molecular characteristics, such as the occurrence of oxidative stress, protein misfolding, and calcium dyshomeostasis (Gorman, 2008). Specifically, $\mathrm{Ca}^{2+}$ dysregulation has been suggested to contribute to the etiology as well as progression of various neurological diseases (Bezprozvanny, 2009; Nikoletopoulou and Tavernarakis, 2012), including Parkinson's disease (Chan et al., 2007; Gandhi et al., 2009; Surmeier et al., 2010), Alzheimer's disease (Bojarski et al., 2008), amyotrophic lateral sclerosis (Grosskreutz et al., 2010), and Huntington's disease (Giacomello et al., 2011; Wu et al., 2011). Particularly relevant to intracellular $\mathrm{Ca}^{2+}$ homeostasis is the family of Transient Receptor Potential (TRP) channels, known to be involved in initiating $\mathrm{Ca}^{2+}$ entry pathways as well as maintaining cytosolic, endoplasmic reticulum (ER), and mitochondrial $\mathrm{Ca}^{2+}$ levels (Gees et al., 2010). Because of their role in ion homeostasis and their expression in the nervous system, TRP channels have been increasingly considered as contributing factors to neuronal degeneration (Selvaraj et al., 2010; Vennekens et al., 2012), but their precise role in degenerative conditions is largely unexplored. Furthermore, mutations in TRP channel family have not been previously implicated as causal to dopaminergic degeneration.

Given the importance of studying the genetic basis of neurodegenerative conditions, it is perhaps surprising that only a few model system studies have attempted to screen in an unbiased manner for mutants in which neurons initially develop but progressively degenerate. We have undertaken such an approach and 
describe here a novel Caenorhabditis elegans mutant with robust and progressive degeneration of dopaminergic neurons during postembryonic development. We show that a single amino acid substitution in a TRP channel is responsible for the phenotype, implicating mutations in TRP family channels as a direct cause of dopaminergic degeneration for the first time. We provide insights on the mode of cell death and the downstream mechanisms of action, revealing the involvement of intracellular $\mathrm{Ca}^{2+}$ homeostasis in the process of dopaminergic cell death.

\section{Materials and Methods}

C. elegans strains. Strains were maintained as previously described (Brenner, 1974). C. elegans hermaphrodites were used in all experiments, unless otherwise stated. Strains used were as follows: BY200: vtIs1 [dat1::gfp;rol-6(d)]; MDH26: trp-4(ot337);vtIs1; MDH41: vtIs1;norEx38[dat1::trp-4(d);ttx-3::cherry];:tIs1; MDH43: norEx40[dat-1::trp-4(d);ttx-3:: cherry];vtIs1, OH6071: trp-4(ot337);vtIs1,vsIs33[dop-3::rfp]; MDH233: trp-4(ot337);eri-1(mg366);lin15B(n744);vtIs1; MDH123: trp-4(ot337); unc-79(e1068),ced-4(n1162);vtIs1,vsIs33; MDH86: unc-79(e1068)ced4(n1162); vtIs1,vsIs33; MDH124: trp-4(ot337); ced-3(n717);vtIs1,vsIs33; MDH51: ced-3(n717); vtIs1,vsIs33. OH9051: otIs259[dat-1::gfp]; MDH28: trp-4(ot337);otIs259; MDH22: crt-1(bz29);otIs259; MDH23: trp4(ot337);crt-1(bz29);otIs259; MDH20: crt-1(ok948);otIs259; MDH21: trp-4(ot337);crt-1(ok948);otIs259; MDH90: itr-1(sa73);vtIs1; MDH89: itr-1(sa73);trp-4(ot337);vtIs1; MDH126: cnx-1(ok2234);vtIs1; MDH127: trp-4(ot337); cnx-1(ok2234); vtIs1; MDH128: cnx-1 (ok2234);crt-1(bz29); trp-4(ot337);otIs259. bxIs19[Ptrp-4::gfp,ttx-3::gfp]; MDH84: crt1(ok948);bxIs19; MDH141: dat-1(ok157);trp-4(ot337);vtIs1; MDH112: cat-2(e1112);vtIs1; MDH129: cat-2(e1112);trp-4(ot337);vtIs1; MDH66: norEx7[dat-1::hcalbindin-1;ttx-3::cherry];trp-4(ot337);vtIs1; MDH119: norEx34[dat-1::hcalbindin-1;ttx-3::cherry];trp-4(ot337);vtIs1; MDH121: norEx36[dat-1::hcalbindin-1;ttx-3::cherry]; trp-4(ot337);vtIs1; MDH97: norEx24[dat-1::mdh-1;ttx-3::mcherry];trp-4(ot337);vtIs1; MDH98: norEx25[dat-1::mdh-1;ttx-3::mcherry];trp-4(ot337);vtIs1; MDH99: norEx26[dat-1::mdh-1;ttx-3::mcherry];trp-4(ot337);vtIs1; MDH138: bxIs19[trp-4::gfp;ttx-3::gfp]; otIs181 [dat-1::mcherry;ttx-3::mcherry]; MDH139: dpy-11(e224) unc-68(e450);trp-4(ot337);otIs259; MDH140: dpy-11(e224),unc-68((e450);otIs259; MDH150: norEx47 [dat-1::GFPTRP-4;rol-6]; MDH169: crt-1(ok948);norEx47[dat-1::GFP-TRP-4;rol-6]; and MDH225: norEx82[Posm-6::trp-4(d);rol-6;ttx-3];oyIs59[Posm$6:: g f p]$.

Mapping and cloning of trp-4(d) mutants. The ot337 allele was mapped on the right arm of CHRI (+14 to $+26 \mathrm{cM})$ using highthroughput SNP mapping (Davis et al., 2005). Both ot 337 and ot 477 alleles were whole-genome sequenced using an Illumina platform followed by data analysis as previously described (Bigelow et al., 2009). Only one locus, $\operatorname{trp}-4$, was affected in common in the two alleles. The mutation was confirmed by Sanger sequencing. We phenocopied the effect of the ot 337 mutation by introducing a $\operatorname{trp}-4(d)$ transgene in a wild-type background. To this end, a plasmid containing the trp-4 cDNA under the control of dat-1 promoter (kindly provided by Shawn Xu) was used to introduce the ot 337 mutation by site-directed mutagenesis.

Ectopic expression of $\operatorname{trp}-4(d): \operatorname{trp}-4(d)$ cDNA followed by unc-54 3'UTR was cloned under the osm-6 promoter (Collet et al., 1998) and injected into oyIs59 worms expressing osm-6::GFP at $30 \mathrm{ng} / \mu \mathrm{l}$, along with $60 \mathrm{ng} / \mu \mathrm{l} \mathrm{rol}-6$ and $50 \mathrm{ng} / \mu \mathrm{lttx}-3::$ mcherry. Worms containing the $t t x-3::$ mcherry coinjection marker were scored for degeneration of ADE, PHA, PHB, and PQR neurons.

Suppressor screen on ot 337 mutants. For the suppressor screen, trp4(ot337) mutant worms were mutagenized using ethyl methanesulfonate (EMS) and standard protocols (Brenner, 1974; Doitsidou et al., 2008). An automated screen was performed using the COPAS Biosorter (Union Biometrica) as previously described (Doitsidou et al., 2008) with the sorting region set to select worms that had gained GFP signal.

Degeneration assays. Well-fed worms raised at $20^{\circ} \mathrm{C}$ for at least two generations were scored as freshly hatched L1s and/or mid L4 stage.
Neurons were scored for cell body presence and morphology as well as axodentritic integrity.

RNAi assays. RNAi assays were performed using a bacterial feeding protocol (Kamath and Ahringer, 2003) and a C. elegans strain with a sensitized genetic background: eri-1;lin15b (Wang et al., 2005).

Fluorescence intensity quantification. Fluorescence intensity measurements were done as previously described (Gavet and Pines, 2010) using ImageJ (Schneider et al., 2012). The fluorescence was represented as Corrected Total Cell Fluorescence $(\mathrm{CTCF})$ where, $\mathrm{CTCF}=$ Integrated Density - (Area of the selected cell $\times$ Mean fluorescence of background readings). Worms in lateral orientation were selected for analysis and fluorescent intensity was separately determined for proximal and distal CEPDs or CEPVs.

Chemical treatments. For the dantrolene and EGTA assays, dantrolene $(10 \mu \mathrm{M})$ in DMSO or EGTA $(10 \mathrm{~mm})$ from Sigma was added to NGM plates (prepared without $\mathrm{CaCl}_{2}$ ). For the BAPTA-AM assays, BAPTAAM (Life Technologies) in DMSO was added to NGM plates (minus $\mathrm{CaCl}_{2}$ ) at a final concentration of $100 \mu \mathrm{M}$. Progeny of worms grown on these plates were scored.

Behavioral assay. The basal slowing response was measured according to Sawin et al. (2000) with the following modifications: worms were video recorded and their velocities were calculated using WormLab 2.0 software (MBF Biosciences).

Statistical analysis. Prism6 (GraphPad) was used for statistical analysis. The sample size was $\geq 50$ for all data points. For comparison of two means, the unpaired two-tailed $t$ test was used. For more than two means, one-way ANOVA, and for group comparisons, two-way ANOVA were used. Multiple comparisons of the means were done by either Tukey's or Sidak's post hoc test; $p$ values $<0.05$ were considered to be statistically significant.

\section{Results}

Isolation of $C$. elegans mutants with progressive degeneration of dopaminergic neurons

Dopaminergic neurons are critically involved in various human behaviors and pathologies and it has been a long-standing goal to understand how these neurons develop and maintain their differentiated properties. The 302-cell nervous system of a C. elegans hermaphrodite contains exactly eight dopaminergic neurons (a pair each of CEPVs, CEPDs, ADEs, and PDEs), making it easy to monitor the presence and integrity of these neurons in living animals with fluorescent protein labeling. Using a semiautomated selection scheme implemented by the COPAS Biosorter technology (Pulak, 2006; Doitsidou et al., 2008), we screened for EMS-mutagenized animals in which dopaminergic neurons were lost (Doitsidou et al., 2008). This phenotype could be caused either by a failure to execute the appropriate developmental program or by a failure to maintain the integrity of dopaminergic neurons after they are formed. This screen did indeed result in the identification of gene regulatory factors involved in dopaminergic neuron development (Doitsidou et al., 2008, 2013; Flames and Hobert, 2009). However, two viable mutants that we have not previously described, ot337 and ot477, showed normal development of these neurons, i.e., in late stage embryos, the complete set of dopaminergic neurons is present (Fig. 1 A,B). Yet, in adult animals, the majority of dopaminergic neurons are lost (which is the phenotype the mutants were selected for; Fig. $1 A, B)$. Analysis of animals from different stages showed that in both alleles the loss of dopaminergic neurons is progressive (Fig. $1 B$; data not shown). Moreover, the progressive neurodegeneration phenotype of the ot337 and ot 477 alleles is semidominant, with heterozygous animals showing degeneration of their dopaminergic neurons, albeit to a lesser degree than the homozygous animals (Fig. 1C). Furthermore, we observed that only the head dopaminergic neurons were affected in these mutants whereas no degeneration was observed in the postembryonically generated 


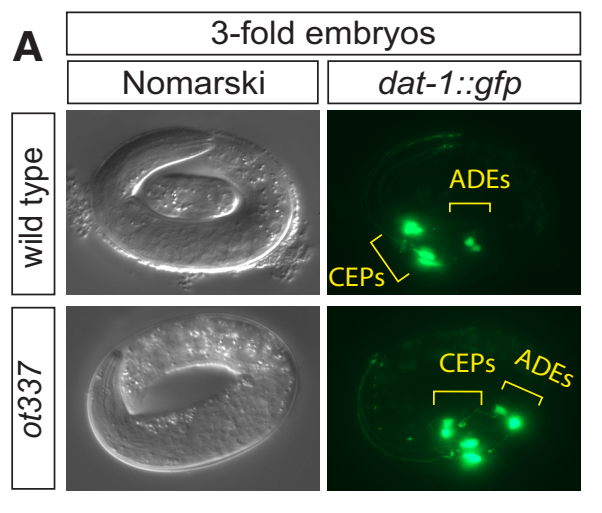

B

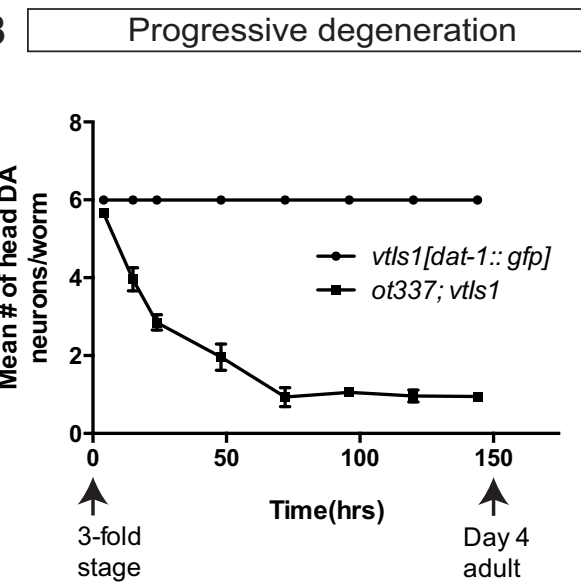

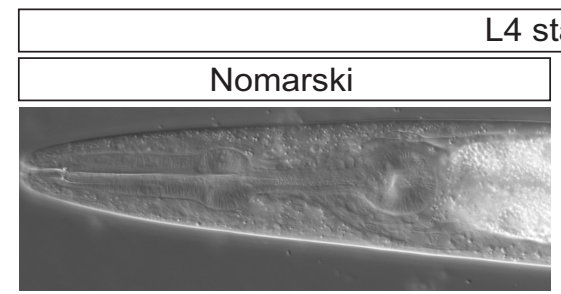

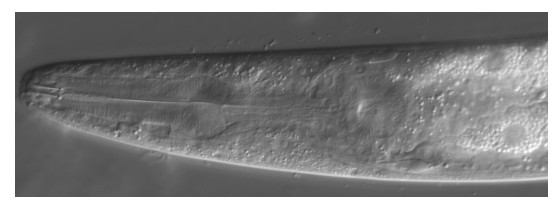

C Semi-dominance of ot337

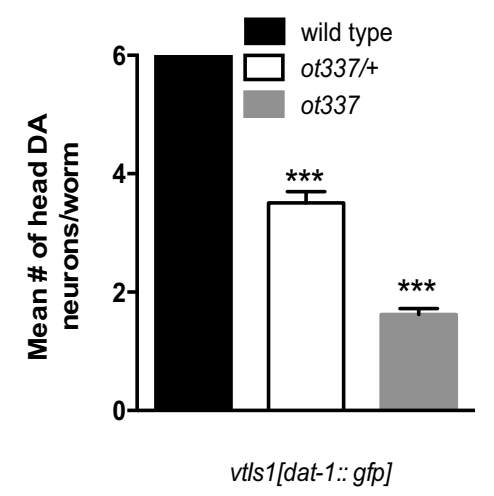

D Effect on DA neuronal classes
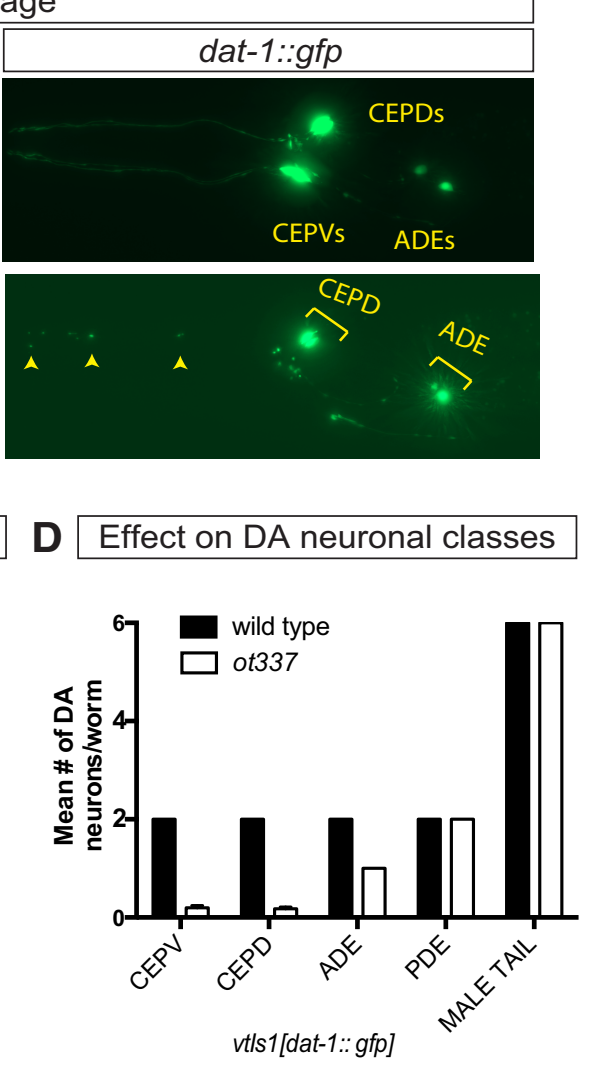

Figure 1. Selective loss of dopaminergic neurons in ot 337 mutants. $\boldsymbol{A}, \boldsymbol{B}$, Progressive loss of dopaminergic (DA) neurons labeled with dat-1::gfp (vt/s1) in ot337 mutants. Arrowheads indicate degenerating CEPD dendrite. C, ot337 mutants are semidominant. $\boldsymbol{D}$, Cell-type specificity of dopaminergic neuron loss. Error bars represent \pm SEM around the mean, ${ }^{* * *} p<0.001$.

mid-body PDE neurons and the male tail dopaminergic neurons (Fig. 1D).

\section{A gain-of-function mutation in the TRP channel trp-4 causes degeneration}

We mapped both ot337 and ot477 on the right arm of chromosome I and identified the molecular lesions through wholegenome sequencing. Both alleles, which were independently isolated, showed a small number of variants in protein-coding genes on chromosome I, yet only one locus was affected in both strains (Fig. 2A). This locus, termed trp-4 (Li et al., 2006), encodes a TRPN-type channel of the TRP six-transmembrane channel family. TRP-4 protein was previously described as a cellsurface mechanoreceptor expressed in dopaminergic neurons ( $\mathrm{Li}$ et al., 2006; Kang et al., 2010; Li et al., 2011). Both of the mutations that we isolated affect the same amino acid in the poreforming sixth transmembrane helix of TRP-4 (Fig. 2B,C). Substitutions in adjacent amino acids in TRP channel orthologs in yeast were previously shown to be gain-of-function mutations resulting in gate destabilization and a higher probability of the channel being in an open state (Su et al., 2007; Zhou et al., 2007).

To confirm that the identified dominant $\operatorname{trp}-4$ mutations in ot337 and ot 477 are indeed responsible for the degeneration phenotype, we conducted reversion-of-phenotype screens, reasoning that the neurodegeneration phenotype should be suppressed by loss-of-function mutations in trp-4. We mutagenized ot337 animals that express GFP in their dopaminergic neurons and screened using the semi-automated selection scheme. We identified 16 mutants in which the GFP signal in adult animals is restored, thus indicating that the normally susceptible dopaminergic neurons do not degenerate. All 16 suppressor mutants contain presumptive loss-of-function mutations in trp-4, including several premature stop codons, deletions, and splice site mutations (Fig. 2C) indicating that ot337 allele harbors a gain-offunction mutation. Apart from confirming that the trp-4(ot337) substitution is indeed the phenotype-causing mutation, the retrieved suppressor mutants may also provide some insights about functionally important residues of the TRP-4 protein. Specifically, $\operatorname{trp}-4$ (ot749) results in an alanine to valine substitution $(\mathrm{A} 1064 \mathrm{~V})$ of a highly conserved alanine of the $21 \mathrm{st}$ ankyrin repeat, $\operatorname{trp}-4$ (ot756) in a substitution of a highly conserved glycine (G1735R) in the pore-forming region, trp4(ot755) in a proline to leucine substitution (P1749L) between the pore-forming region and the sixth transmembrane domain, and $\operatorname{trp}$-4(ot757) carries two mutations in the cytosolic C-terminal tail of TRP-4 (R1845C+L1876H).

To further confirm the degeneration effects of the trp4(ot337) locus, a trp-4 cDNA that carries the ot 337 mutation was expressed under the control of a dopamine neuron-specific promoter from the dat-1 (dopamine transporter) locus. Transgenic animals expressing this construct recapitulated the dopaminergic neuron degeneration phenotype (Fig. 2D). Moreover, in these transgenic animals we observed robust degeneration of all dopaminergic neuronal classes, including PDEs and male tail dopaminergic neurons, which do not typically degenerate in the ot337 mutants. Since transgenic arrays are usually multicopy in C. elegans, we interpret this finding as an indication of the importance of gene dosage. 
A

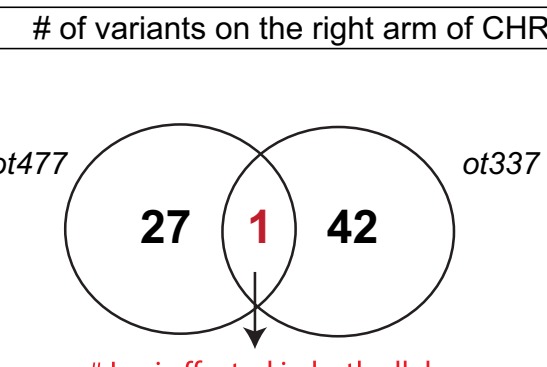

\# Loci affected in both alleles
B

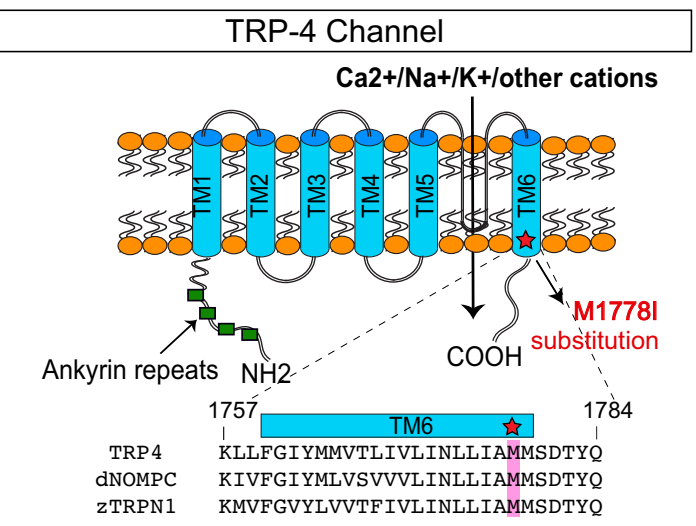

C trp-4 intragenic revertants retrieved in ot337 suppression screen
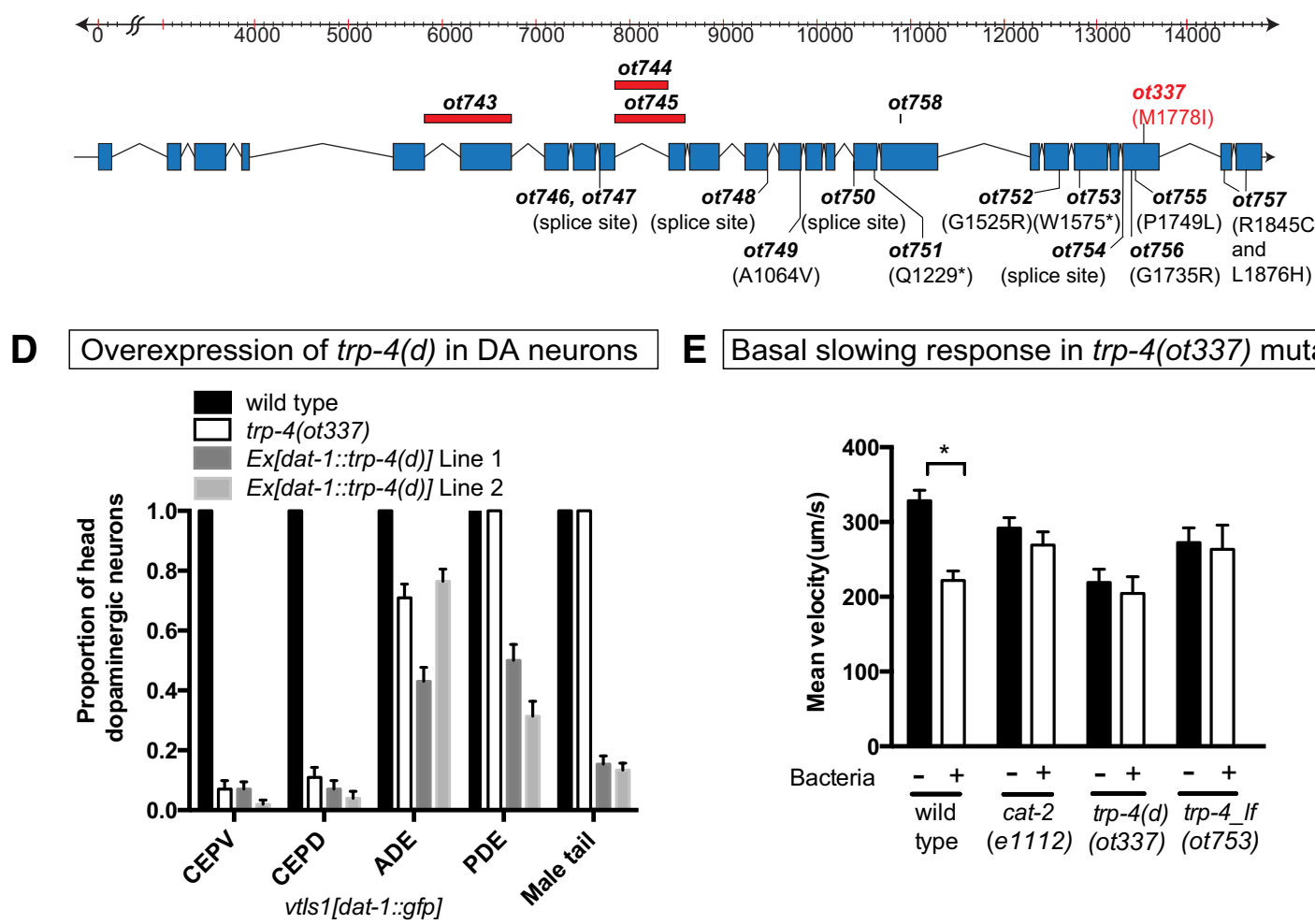

E Basal slowing response in trp-4(ot337) mutants

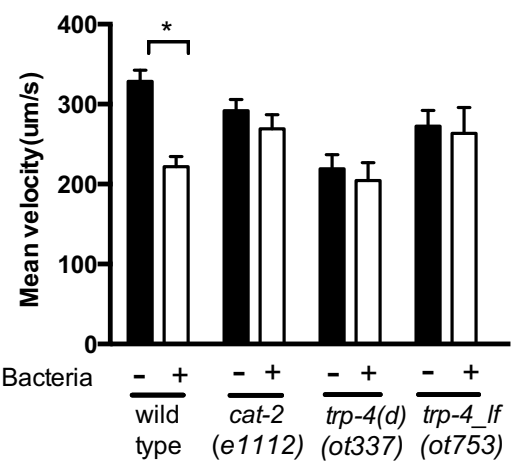

Figure 2. Molecular characterization of trp-4. A, Venn diagram depicting the number of molecular lesions identified in two whole-genome sequenced alleles, ot 477 and ot337. 0 nly one locus within the mapping region was affected in both strains (trp-4). B, Schematic drawing of the predicted structure of TRP-4 channel (based on alignment with the Drosophila ortholog NOMPC; Walker et al., 2000). Location of the gain-of-function allele is depicted (star) and alignment of the region adjacent to the sixth transmembrane domain, bearing the ot337 mutation. dNOMPC and zTRPN are, respectively, the Drosophila and zebrafish orthologs of trp-4. C, trp-4 locus with gain-of-function mutation ot337 and intragenic suppressor mutations. D, Transgenic animals containing trp-4(d) CDNA expressed under control of the dat- 1 promoter show degeneration phenotype in their dopaminergic (DA) neurons. $\boldsymbol{E}$, Basal slowing response in trp-4(ot337) mutants is defective (If: loss of function). Error bars represent \pm SEM around the mean, ${ }^{* * *} p<0.001$.

To assess the behavioral consequences of the ot 337 mutation in the TRP-4 channel, we measured the basal slowing response in the $\operatorname{trp}-4(d)$ mutants. This is a previously characterized dopamine-dependent behavioral response mediated redundantly by the various classes of dopamine neurons as a result of mechanosensory stimuli presented by food (Sawin et al., 2000). Well-fed, wild-type worms showed a distinctive slowing behavior in the presence of food as assessed by locomotion velocity (Fig. $2 E$ ), which was abolished in dopamine-deficient cat-2 mutants. $\operatorname{trp}-4$ (d) mutants were equally defective in basal slowing response, despite the fact that not all dopaminergic neurons degenerate in these mutants. Similar defects in basal slowing response are observed in trp-4 loss-of-function mutants (Kang et al., 2010; Figure 2E), indicating that the ot337 gain-of-function allele is defective for at least some aspects of the TRP-4 channel function.

\section{$\operatorname{trp}-4(d)$ degeneration is dopamine independent}

trp-4 is expressed in all dopaminergic neurons, as previously reported (Li et al., 2006), and as assessed by us using a previously described reporter gene construct (Barrios et al., 2008; data not shown). trp-4 is also expressed in 14 additional neurons in the head (data not shown) and in the DVA and DVC tail neurons ( $\mathrm{Li}$ et al., 2006). In addition to dopaminergic neurons, a degeneration phenotype was observed in other trp- 

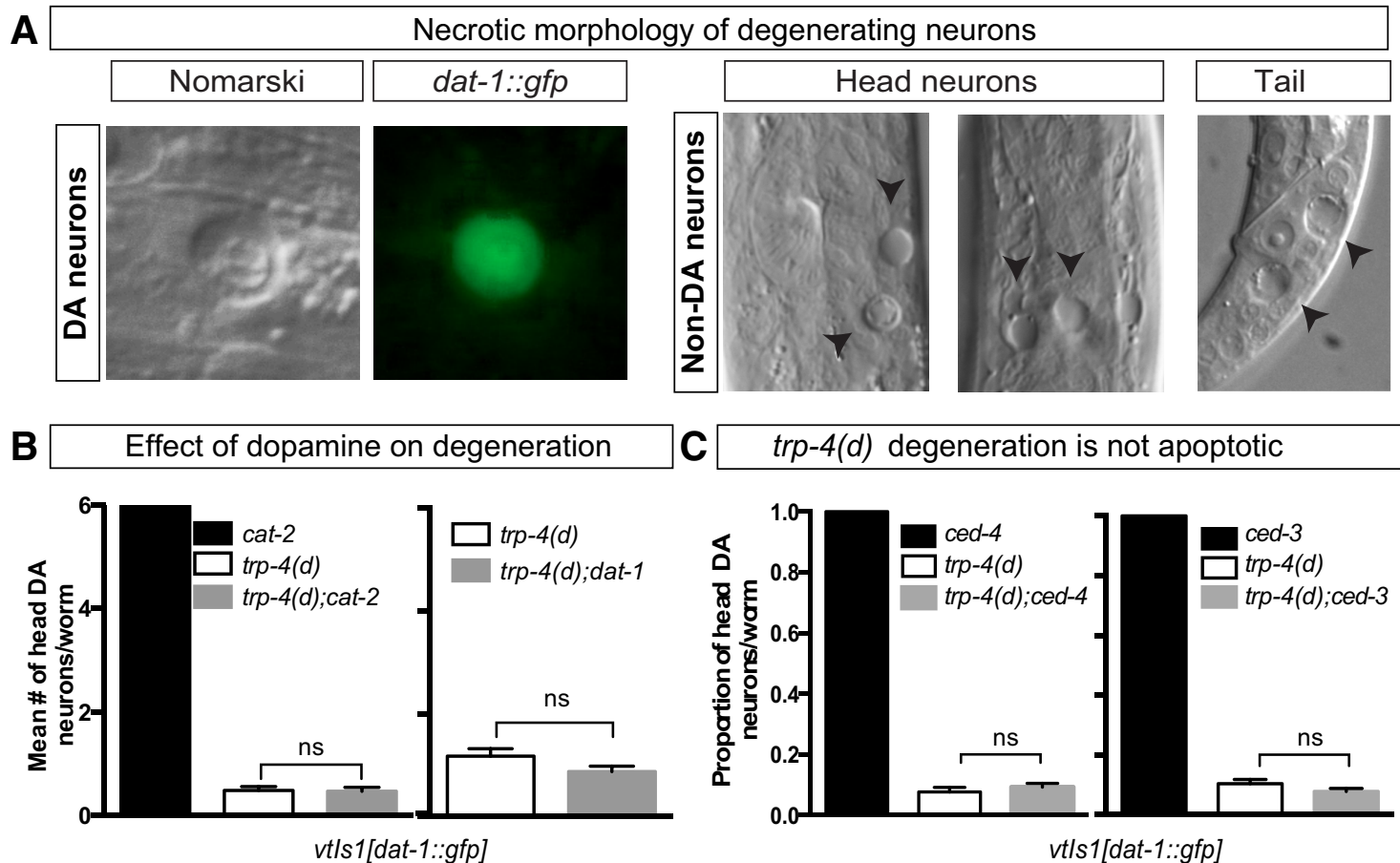

Figure 3. Characteristics of cell death in trp-4(d) mutants. $A$, Necrotic morphology of degenerating dopaminergic (DA) and non-dopaminergic neuronal types in trp-4(d) animals (cell swelling). Eventually the cell bodies disappear. Arrowheads point to cell bodies with necrotic morphology. B, Degeneration does not depend on dopamine. cat-2 and dat- 1 mutations do not suppress trp-4(d) dopaminergic degeneration. trp-4(d)-induced degeneration does not depend on intracellular dopamine levels. $C$, The trp-4(d) phenotype is not suppressed by apoptotic mutants, ced-4 and ced-3. Error bars represent \pm SEM around the mean. ns: $p>0.05$.

4-expressing neuronal cell types including the DVA and DVC neurons (Fig. 3A). Consistent with the observation that degeneration is not dopaminergic neuron specific, we find that the degree of degeneration does not depend on dopamine levels: neither removal of dopamine in cat-2 mutants (the $C$. elegans ortholog of tyrosine hydroxylase, catalyzing the ratelimiting step in dopamine synthesis) nor interfering with dopamine reuptake from the synapse in dat-1 mutants (dopamine transporter) had any effect on the severity of dopaminergic degeneration (Fig. 3B).

TRP-4(d) channel does not cause degeneration in all neuronal types when ectopically expressed

Since degeneration in $\operatorname{trp}-4(d)$ mutants is not dependent on dopamine or dopaminergic neuron specific, we tested whether the mutated TRP-4(d) channel can induce degeneration in other neuronal subtypes where it is normally not expressed. We ectopically expressed the mutated channel under the control of $o s m-6$ promoter and used an $o s m-6:: g f p$ transgenic background to visualize the relevant neurons. osm- 6 is expressed in the majority of ciliated neurons (56 neurons, including the dopaminergic neuronal classes; Collet et al., 1998). To bypass quantification difficulties due to the high density of osm-6-expressing neurons near the nerve ring, we focused our analysis on the more posterior osm-6-expressing neuronal classes: the dopaminergic ADEs that normally express TRP-4, and the tail neurons PHA ( $\mathrm{L}$ and $\mathrm{R}$ ), $\mathrm{PHB}$ (L and R), and PQR that do not normally express TRP-4. In Posm-6::trp-4(d) transgenic worms, PHA, PHB, and PQR neuronal classes remained unaffected, in contrast to the ADEs that degenerated in $>80 \%$ of the worms. Furthermore, we did not observe any obvious degeneration phenotype in the osm-6-expressing neurons around the nerve ring (data not shown). Thus, TRP-4(d) was not able to induce degeneration ectopically in all neuronal subtypes.

\section{$\operatorname{trp}-4(d)$ degeneration of dopaminergic neurons is} independent of apoptosis and exhibits characteristics of necrosis

Even though progressive dopaminergic neurodegeneration has not yet been directly associated with TRP-type ion channels, a few cases of TRP channelopathies affecting other neuronal subtypes have been reported in humans (Kremeyer et al., 2010; Nilius and Owsianik, 2010). In addition, at least three in vivo animal models of gain-of-function mutations in TRP channels have been identified: one in flies, affecting photoreceptors (Yoon et al., 2000); two in mice, affecting sensory hair cells (Waddler mouse) and Purkinje cells (moonwalker mouse; Kim et al., 2007; Becker et al., 2009). These TRP gain-of-function models result in degenerative phenotypes, but the nature of cell death has not been characterized. We examined trp-4(ot337) mutant animals in more detail and noted that dopaminergic neurons show features characteristic of necrosis, which in addition to apoptosis and autophagy, is one of the three best characterized cell death pathways (Edinger and Thompson, 2004). In contrast to apoptotic cells that show characteristic shrinking and blebbing morphology, necrotic cells swell before they disintegrate, a phenotype that we observed in $\operatorname{trp}-4(d)$ mutants (Fig. 3A). Furthermore, mutations that eliminate two executioners of apoptosis, ced-3 and ced-4, have no effect on $\operatorname{trp}$-4(ot337)-induced degeneration (Fig. 3C), ruling out involvement of the apoptotic cell death pathway.

Involvement of intracellular $\mathrm{Ca}^{2+}$ and exit of $\mathrm{Ca}^{2+}$ from the ER in $\operatorname{trp}-4(d)$ neurodegeneration

Members of the TRP channel family are mostly nonspecific cation channels, able to conduct monovalent as well as bivalent 
A

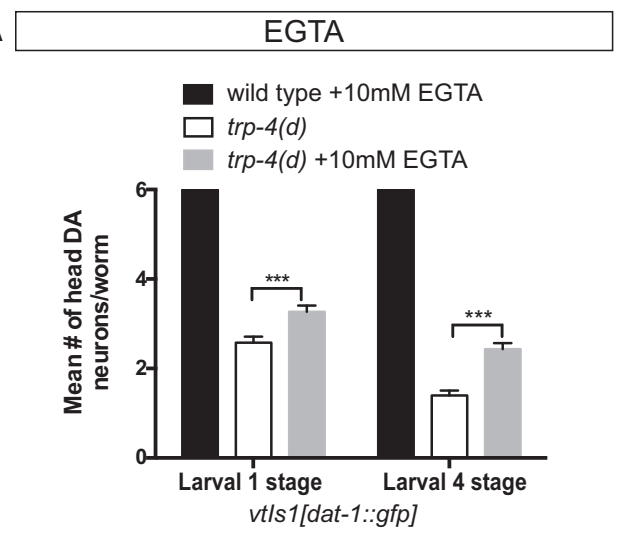

C

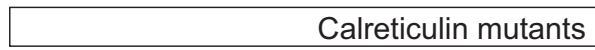

B

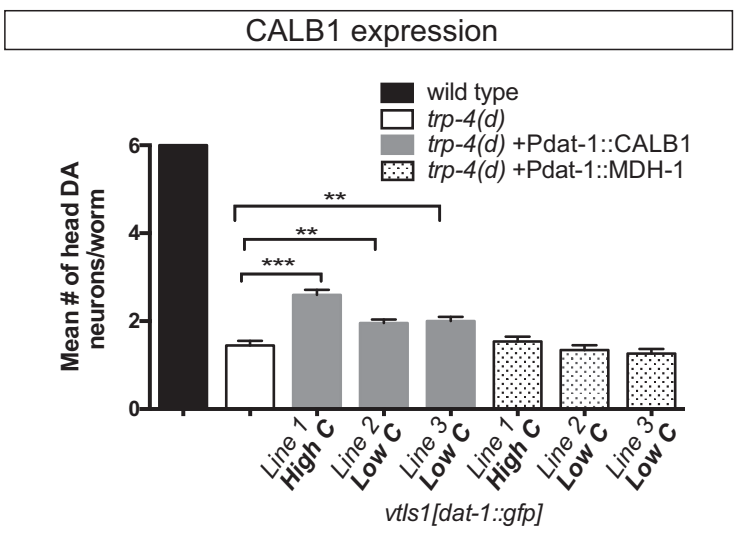

on trp-4(d) degeneration
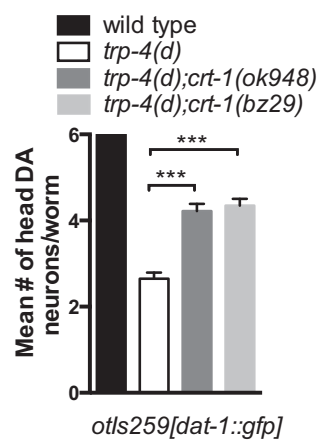

$\mathbf{E}$

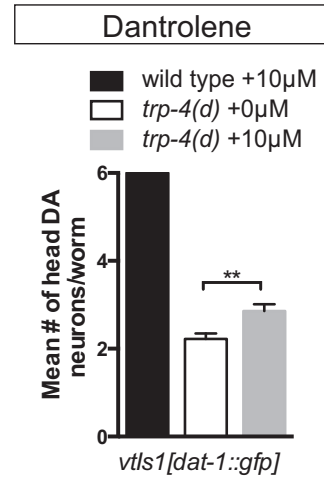

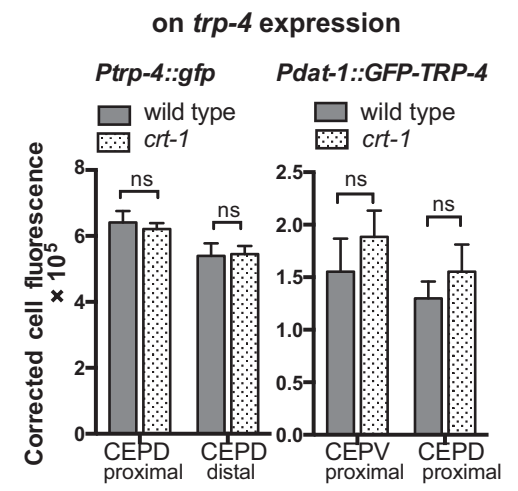

$\mathbf{D}$

Calnexin mutants
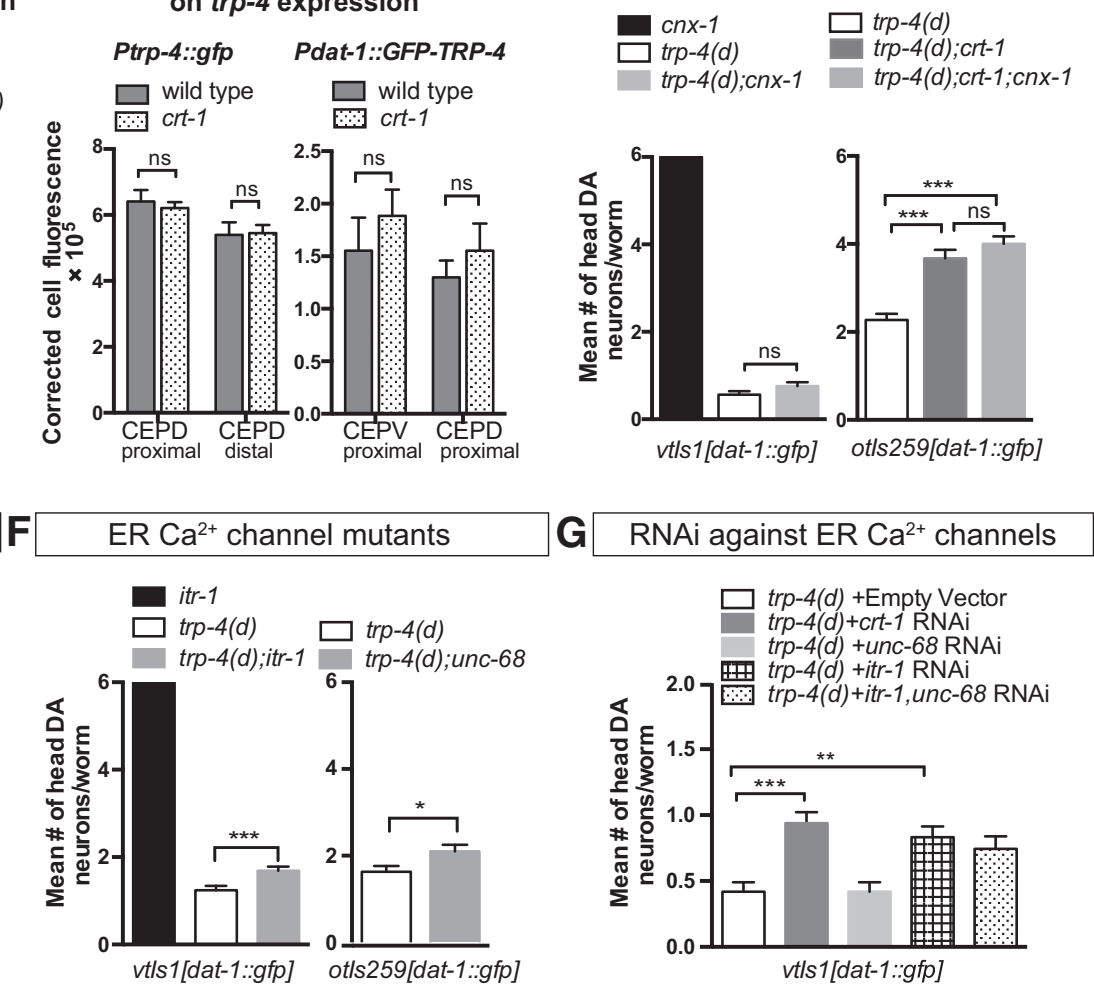

H

Dantrolene on calreticulin mutants
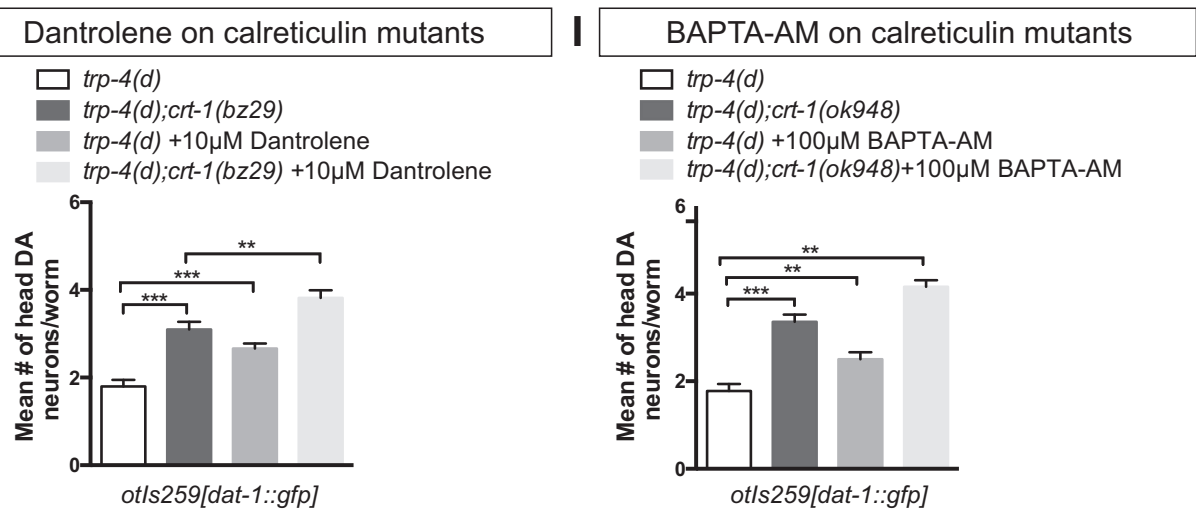

Figure 4. Involvement of intracellular $\mathrm{Ca}^{2+}$ and exit of $\mathrm{Ca}^{2+}$ from the ER in trp-4(d) neurodegeneration. $\boldsymbol{A}$, Chelating cytoplasmic calcium with EGTA suppresses trp-4(d)-induced neuronal degeneration. $\boldsymbol{B}$, Expression of human calbindin (CALB1) suppresses trp-4(d)-induced neuronal degeneration (injected concentrations: Line $1=25 \mathrm{ng} . \mu \mathrm{l}$, lines $2,3=7.5 \mathrm{ng} / \mu \mathrm{l})$. Corresponding negative control, expression of malate dehydrogenase ( $m d h-1 b$ ), had no effect. C, Left, Calreticulin (crt-1) mutation suppresses trp-4(d)-induced dopaminergic (DA) degeneration. Middle and right, Calreticulin mutation does not affect Ptrp-4::gfp or Pdat-1::GFP-TRP-4 expression levels. Average fluorescent intensities of the indicated CEPs were calculated (see Materials and Methods). D, Calnexin does not affect trp-4(d)-induced neuronal degeneration. $\boldsymbol{E}$, Dantrolene suppresses trp-4(d)-induced neuronal degeneration. $\boldsymbol{F}$, Mutations in the ER inositol triphosphate and ryanodine receptors partially suppress trp-4(d)-induced dopaminergic neuronal degeneration.G, RNAi against ryanodine receptors on trp-4(d) mutants.The RNAi "sensitized" strain (Figure legend continues.) 
cations (Venkatachalam and Montell, 2007). With the exceptions of TRPM4 and TRPM5, which are only permeable to monovalent cations, all functionally characterized TRP channels are permeable to $\mathrm{Ca}^{2+}$. To explore the possibility that intracellular $\mathrm{Ca}^{2+}$ dyshomeostasis is a contributing factor in $\operatorname{trp}-4(d)$-induced degeneration, cytoplasmic $\mathrm{Ca}^{2+}$ was pharmacologically and genetically chelated in these mutants. Treatment of $\operatorname{trp}-4(d)$ mutants with EGTA significantly suppressed dopaminergic degeneration (Fig. 4A). Another way to chelate cytoplasmic $\mathrm{Ca}^{2+}$ is to overexpress an intracellular "calcium sink," such as calbindin, a $\mathrm{Ca}^{2+}$ binding protein (Mattson et al., 1991). trp-4(d) worms expressing human calbindin (CALB1) under the control of the dat-1 promoter exhibited significantly lower levels of neuronal loss, whereas no such effect was observed when a non-calcium binding gene was expressed (Fig. 4B).

Other types of channelopathies involving DEG/ENaC-type ion channels also result in necrotic cell death and involve specific downstream components that regulate $\mathrm{Ca}^{2+}$ storage in the ER (Xu et al., 2001; Barbagallo et al., 2010). Exit of $\mathrm{Ca}^{2+}$ from the ER as a response to hyperactivated DEG/ENaC channels was shown to contribute to neuronal cell death (Xu et al., 2001; Bianchi et al., 2004; Barbagallo et al., 2010). We tested the involvement of these components in trp-4(d)-induced neurodegeneration. Loss-offunction mutants of the $\mathrm{Ca}^{2+}$ binding ER chaperone calreticulin (crt-1), the main ER $\mathrm{Ca}^{2+}$ store, significantly suppressed dopaminergic degeneration (Fig. 4C). trp-4 transcript and TRP-4 protein levels were unaffected in $c r t-1$ mutants (Fig. 4C). Mutations in another ER chaperone, calnexin (cnx-1), which has comparatively less $\mathrm{Ca}^{2+}$-binding capacity than CRT-1 (Groenendyk et al., 2006), neither suppressed degeneration nor enhanced the effects of crt-1 mutants (Fig. 4D).

In agreement with a role for $\mathrm{ER} \mathrm{Ca}^{2+}$ exit in $\operatorname{trp}-4(d)$-induced neurodegeneration, pharmacological inhibition of $\mathrm{Ca}^{2+}$ exit from the ER in $\operatorname{trp}-4(d)$ mutants using the ryanodine receptor antagonist dantrolene (Zhao et al., 2001) partially suppressed dopaminergic neurodegeneration (Fig. 4E). Similar results were obtained using mutations in channels responsible for $\mathrm{Ca}^{2+}$ exit from the ER, in particular inositol triphosphate receptor (itr-1) and $u n c-68$ (a ryanodine receptor; Fig. $4 F$ ), as well as with RNAi treatment against itr-1 in trp-4(d) mutants (Fig. 4G).

Combining the genetic depletion of $\mathrm{Ca}^{2+}$ store in the ER with the pharmacological inhibition of ryanodine receptors resulted in a stronger suppression of $\operatorname{trp}-4(d)$ degeneration than each treatment alone (Fig. 4H). Furthermore, when double mutants for $c r t-1$ and $\operatorname{trp}-4(d)$ were treated with BAPTA-AM, a membrane-permeable calcium chelator, the result was an additive effect in the suppression levels of dopaminergic degeneration (Fig. 4I).

\section{Discussion}

Here we introduce a novel model for a neurodegenerative channelopathy, showing that gain-of-function mutations in a TRP ion channel cause progressive loss of dopaminergic neurons as well as other neuronal types. We have shown that dopaminergic neurons die through mechanisms independent from classical apoptosis

\section{$\leftarrow$}

(Figure legend continued.) trp-4(ot337);eri-1;/in15b;vtls7 was used. $\boldsymbol{H}$, Combining genetic deletion of $\mathrm{crt}-1$ and pharmacologic inhibition of ryanodine receptors results in stronger suppression of degeneration. I, Combining genetic deletion of $\mathrm{crt}-1$ and intracellular $\mathrm{Ca}^{2+}$ chelation with BAPTA-AM results in stronger suppression of degeneration. In all parts, we refer to the trp$4\left(\right.$ ot337) allele as trp- 4 (d). Error bars represent \pm SEM around the mean. ns: $p>0.05,{ }^{*} p<$ $0.05,{ }^{* *} p<0.01,{ }^{* * *} p<0.001$. pathways, and that the dying cells exhibit morphological characteristics of necrotic cell death. Furthermore, we provide evidence that intracellular calcium homeostasis as well as calcium exit from the ER contribute to the process of $\operatorname{trp}-4(d)$-induced neuronal cell death.

The many ways in which $\mathrm{Ca}^{2+}$ influx can occur across the plasma membrane include voltage-gated, ligand-gated, receptoroperated, and store-operated $\mathrm{Ca}^{2+}$ channels (Brini et al., 2014). TRP channel family members are not only highly permeable to $\mathrm{Ca}^{2+}$, but also have been shown to participate in the above mechanisms of $\mathrm{Ca}^{2+}$ signaling and influx (Gees et al., 2010). In relevance to degeneration, cases of gain-of-function mutations in TRP channels have been reported that cause an increased calcium influx (Reiser et al., 2005; Grimm et al., 2007; Kim et al., 2007; Klein et al., 2011). Furthermore, members of TRPC channel family were shown to contribute to the mechanism of Huntington's disease, through interaction with the store-operated $\mathrm{Ca}^{2+}$ entry pathway (Wu et al., 2011) and to mediate glutamate-induced excitotoxic neuronal death by promoting cellular $\mathrm{Ca}^{2+}$ overload (Narayanan et al., 2008). Whether the mutated TRP-4(d) channel conducts toxic levels of $\mathrm{Ca}^{2+}$ directly, or causes $\mathrm{Ca}^{2+}$ dysregulation through indirect mechanisms, remains to be determined. Consistent with a role for membrane depolarization and voltage-gated calcium channel (VGCC) activation in our model, we observed partial suppression of $\operatorname{trp}-4(d)$ degeneration in knockdown experiments of some (cca-1) but not other (egl-19 and $u n c-2$ ) VGCC $\alpha$-subunits (M. Doitsidou and A. Nagarajan, unpublished data). In vivo experiments that systematically address the involvement of different types of calcium influx pathways (mentioned above) as well as redundancy issues between them will further illuminate the mechanisms of calcium toxicity in TRP-4(d)-mediated dopaminergic degeneration.

According to our observations, the various classes of dopamine neurons are not equally susceptible to $\operatorname{trp}-4(d)$ degeneration: CEPVs and CEPDs show nearly complete degeneration by adult stage, whereas ADEs are only partially affected and PDEs are completely unaffected. Different levels of TRP-4 protein could be partly responsible for their differential susceptibility to degeneration. Indeed, overexpression of the trp-4(d) cDNA in dopamine neurons caused partial degeneration of PDEs. Nevertheless, even through overexpression we were unable to cause PDEs to degenerate as frequently as the head dopaminergic neurons, indicating that there might be intrinsic differences between neuronal classes that render them differentially susceptible to degeneration, for example, availability of channel subunits or downstream effectors of degeneration. In agreement with this hypothesis, introducing TRP-4(d) channel in neurons that normally do not express it was not sufficient to induce degeneration.

Despite the fact that some dopaminergic neurons are spared in $\operatorname{trp}-4(d)$ mutants, their function appears to be defective. Previous ablation studies (Sawin et al., 2000) have shown that various classes of dopaminergic neurons act redundantly to mediate basal slowing response and the presence of PDEs alone is sufficient to elicit this behavior. $\operatorname{trp}-4(d)$ mutants were, in contrast, completely defective for basal slowing response, similar to the trp-4-null or dopamine-deficient mutants, indicating that the presence of the mutated channel in the remaining dopamine neurons has functional consequences.

Mutations in TRP family channels have not been previously implicated in direct degeneration of dopaminergic neurons. Interestingly, an association has been reported between a variant in TRPM7 channels and environmentally triggered Parkinsonism dementia in a population of Guam (Hermosura et al., 2005). 
However, direct evidence that TRPM7 variants are causal to this condition is yet to be obtained. There are 27 members of the TRP channel family in humans (Venkatachalam and Montell, 2007), several of which are known to be expressed in the substantia nigra dopaminergic neurons (Riccio et al., 2002; Tozzi et al., 2003; Guatteo et al., 2005). Among those, TRPC channels have received special attention for their protective role in MPP + models of dopaminergic neurotoxicity (Selvaraj et al., 2009). With the advent of next generation sequencing technologies it would be very pertinent to examine whether TRP channel loci harbor riskmodifying variants for Parkinson's disease.

\section{References}

Barbagallo B, Prescott HA, Boyle P, Climer J, Francis MM (2010) A dominant mutation in a neuronal acetylcholine receptor subunit leads to motor neuron degeneration in Caenorhabditis elegans. J Neurosci 30: 13932-13942. CrossRef Medline

Barrios A, Nurrish S, Emmons SW (2008) Sensory regulation of C. elegans male mate-searching behavior. Curr Biol 18:1865-1871. CrossRef Medline

Becker EB, Oliver PL, Glitsch MD, Banks GT, Achilli F, Hardy A, Nolan PM, Fisher EM, Davies KE (2009) A point mutation in TRPC3 causes abnormal Purkinje cell development and cerebellar ataxia in moonwalker mice. Proc Natl Acad Sci U S A 106:6706-6711. CrossRef Medline

Bezprozvanny I (2009) Calcium signaling and neurodegenerative diseases. Trends Mol Med 15:89-100. CrossRef Medline

Bianchi L, Gerstbrein B, Frøkjaer-Jensen C, Royal DC, Mukherjee G, Royal MA, Xue J, Schafer WR, Driscoll M (2004) The neurotoxic MEC-4(d) $\mathrm{DEG} / \mathrm{ENaC}$ sodium channel conducts calcium: implications for necrosis initiation. Nat Neurosci 7:1337-1344. CrossRef Medline

Bigelow H, Doitsidou M, Sarin S, Hobert O (2009) MAQGene: software to facilitate C. elegans mutant genome sequence analysis. Nat Methods 6:549. CrossRef Medline

Bojarski L, Herms J, Kuznicki J (2008) Calcium dysregulation in Alzheimer's disease. Neurochem Int 52:621-633. CrossRef Medline

Brenner S (1974) The genetics of Caenorhabditis elegans. Genetics 77:7194. Medline

Brini M, Calì T, Ottolini D, Carafoli E (2014) Neuronal calcium signaling: function and dysfunction. Cell Mol Life Sci. Advance online publication. doi:10.1007/s00018-013-1550-7. Jan 19, 2014. CrossRef

Chan CS, Guzman JN, Ilijic E, Mercer JN, Rick C, Tkatch T, Meredith GE, Surmeier DJ (2007) "Rejuvenation" protects neurons in mouse models of Parkinson's disease. Nature 447:1081-1086. CrossRef Medline

Collet J, Spike CA, Lundquist EA, Shaw JE, Herman RK (1998) Analysis of osm-6, a gene that affects sensory cilium structure and sensory neuron function in Caenorhabditis elegans. Genetics 148:187-200. Medline

Davis MW, Hammarlund M, Harrach T, Hullett P, Olsen S, Jorgensen EM (2005) Rapid single nucleotide polymorphism mapping in C. elegans. BMC Genomics 6:118. CrossRef Medline

Doitsidou M, Flames N, Lee AC, Boyanov A, Hobert O (2008) Automated screening for mutants affecting dopaminergic-neuron specification in C. elegans. Nat Methods 5:869-872. CrossRef Medline

Doitsidou M, Flames N, Topalidou I, Abe N, Felton T, Remesal L, Popovitchenko T, Mann R, Chalfie M, Hobert O (2013) A combinatorial regulatory signature controls terminal differentiation of the dopaminergic nervous system in C. elegans. Genes Dev 27:1391-1405. CrossRef Medline

Driscoll M, Chalfie M (1991) The mec-4 gene is a member of a family of Caenorhabditis elegans genes that can mutate to induce neuronal degeneration. Nature 349:588-593. CrossRef Medline

Edinger AL, Thompson CB (2004) Death by design: apoptosis, necrosis and autophagy. Curr Opin Cell Biol 16:663-669. CrossRef Medline

Flames N, Hobert O (2009) Gene regulatory logic of dopamine neuron differentiation. Nature 458:885-889. CrossRef Medline

Gandhi S, Wood-Kaczmar A, Yao Z, Plun-Favreau H, Deas E, Klupsch K, Downward J, Latchman DS, Tabrizi SJ, Wood NW, Duchen MR, Abramov AY (2009) PINK1-associated Parkinson's disease is caused by neuronal vulnerability to calcium-induced cell death. Mol Cell 33:627638. CrossRef Medline

Gavet O, Pines J (2010) Progressive activation of CyclinB1-Cdk1 coordinates entry to mitosis. Dev Cell 18:533-543. CrossRef Medline

Gees M, Colsoul B, Nilius B (2010) The role of transient receptor potential cation channels in $\mathrm{Ca} 2+$ signaling. Cold Spring Harb Perspect Biol 2:a003962. CrossRef Medline

Giacomello M, Hudec R, Lopreiato R (2011) Huntington's disease, calcium, and mitochondria. Biofactors 37:206-218. CrossRef Medline

Gorman AM (2008) Neuronal cell death in neurodegenerative diseases: recurring themes around protein handling. J Cell Mol Med 12:2263-2280. CrossRef Medline

Grimm C, Cuajungco MP, van Aken AF, Schnee M, Jörs S, Kros CJ, Ricci AJ, Heller S (2007) A helix-breaking mutation in TRPML3 leads to constitutive activity underlying deafness in the varitint-waddler mouse. Proc Natl Acad Sci U S A 104:19583-19588. CrossRef Medline

Groenendyk J, Opas M, Michalak M (2006) Protein folding and calcium homeostasis in the endoplasmic reticulum. Calcium Binding Proteins 1:77-85.

Grosskreutz J, Van Den Bosch L, Keller BU (2010) Calcium dysregulation in amyotrophic lateral sclerosis. Cell Calcium 47:165-174. CrossRef Medline

Guatteo E, Chung KK, Bowala TK, Bernardi G, Mercuri NB, Lipski J (2005) Temperature sensitivity of dopaminergic neurons of the substantia nigra pars compacta: involvement of transient receptor potential channels. J Neurophysiol 94:3069-3080. CrossRef Medline

Harrington AJ, Hamamichi S, Caldwell GA, Caldwell KA (2010) C. elegans as a model organism to investigate molecular pathways involved with Parkinson's disease. Dev Dyn 239:1282-1295. CrossRef Medline

Hermosura MC, Nayakanti H, Dorovkov MV, Calderon FR, Ryazanov AG, Haymer DS, Garruto RM (2005) A TRPM7 variant shows altered sensitivity to magnesium that may contribute to the pathogenesis of two Guamanian neurodegenerative disorders. Proc Natl Acad Sci U S A 102: 11510-11515. CrossRef Medline

Hong K, Driscoll M (1994) A transmembrane domain of the putative channel subunit MEC-4 influences mechanotransduction and neurodegeneration in C. elegans. Nature 367:470-473. CrossRef Medline

Kamath RS, Ahringer J (2003) Genome-wide RNAi screening in Caenorhabditis elegans. Methods 30:313-321. CrossRef Medline

Kang L, Gao J, Schafer WR, Xie Z, Xu XZ (2010) C. elegans TRP family protein TRP-4 is a pore-forming subunit of a native mechanotransduction channel. Neuron 67:381-391. CrossRef Medline

Kim HJ, Li Q, Tjon-Kon-Sang S, So I, Kiselyov K, Muallem S (2007) Gainof-function mutation in TRPML3 causes the mouse Varitint-Waddler phenotype. J Biol Chem 282:36138-36142. CrossRef Medline

Klein CJ, Shi Y, Fecto F, Donaghy M, Nicholson G, McEntagart ME, Crosby AH, Wu Y, Lou H, McEvoy KM, Siddique T, Deng HX, Dyck PJ (2011) TRPV4 mutations and cytotoxic hypercalcemia in axonal Charcot-MarieTooth neuropathies. Neurology 76:887-894. CrossRef Medline

Kremeyer B, Lopera F, Cox JJ, Momin A, Rugiero F, Marsh S, Woods CG, Jones NG, Paterson KJ, Fricker FR, Villegas A, Acosta N, Pineda-Trujillo NG, Ramírez JD, Zea J, Burley MW, Bedoya G, Bennett DL, Wood JN, Ruiz-Linares A (2010) A gain-of-function mutation in TRPA1 causes familial episodic pain syndrome. Neuron 66:671-680. CrossRef Medline

Lee Y, Dawson VL, Dawson TM (2012) Animal models of Parkinson's disease: vertebrate genetics. Cold Spring Harb Perspect Med 2: pii: a009324. CrossRef Medline

Lesage S, Brice A (2009) Parkinson's disease: from monogenic forms to genetic susceptibility factors. Hum Mol Genet 18:R48-R59. CrossRef Medline

Li W, Feng Z, Sternberg PW, Xu XZ (2006) A C. elegans stretch receptor neuron revealed by a mechanosensitive TRP channel homologue. Nature 440:684-687. CrossRef Medline

Li W, Kang L, Piggott BJ, Feng Z, Xu XZ (2011) The neural circuits and sensory channels mediating harsh touch sensation in Caenorhabditis elegans. Nat Commun 2:315. CrossRef Medline

Lill CM, Bertram L (2011) Towards unveiling the genetics of neurodegenerative diseases. Semin Neurol 31:531-541. CrossRef Medline

Mattson MP, Rychlik B, Chu C, Christakos S (1991) Evidence for calciumreducing and excito-protective roles for the calcium-binding protein calbindin-D28k in cultured hippocampal neurons. Neuron 6:41-51. CrossRef Medline

Narayanan KL, Irmady K, Subramaniam S, Unsicker K, von Bohlen und Halbach O (2008) Evidence that TRPC1 is involved in hippocampal glutamate-induced cell death. Neurosci Lett 446:117-122. CrossRef Medline

Ni L, Guo P, Reddig K, Mitra M, Li HS (2008) Mutation of a TADR protein 
leads to rhodopsin and Gq-dependent retinal degeneration in Drosophila. J Neurosci 28:13478-13487. CrossRef Medline

Nikoletopoulou V, Tavernarakis N (2012) Calcium homeostasis in aging neurons. Front Genet 3:200. CrossRef Medline

Nilius B, Owsianik G (2010) Transient receptor potential channelopathies. Pflugers Arch 460:437-450. CrossRef Medline

Pulak R (2006) Techniques for analysis, sorting, and dispensing of C. elegans on the COPAS flow-sorting system. Methods Mol Biol 351:275286. Medline

Reiser J, Polu KR, Möller CC, Kenlan P, Altintas MM, Wei C, Faul C, Herbert S, Villegas I, Avila-Casado C, McGee M, Sugimoto H, Brown D, Kalluri R, Mundel P, Smith PL, Clapham DE, Pollak MR (2005) TRPC6 is a glomerular slit diaphragm-associated channel required for normal renal function. Nat Genet 37:739-744. CrossRef Medline

Riccio A, Medhurst AD, Mattei C, Kelsell RE, Calver AR, Randall AD, Benham CD, Pangalos MN (2002) mRNA distribution analysis of human TRPC family in CNS and peripheral tissues. Brain Res Mol Brain Res 109:95-104. CrossRef Medline

Sawin ER, Ranganathan R, Horvitz HR (2000) C. elegans locomotory rate is modulated by the environment through a dopaminergic pathway and by experience through a serotonergic pathway. Neuron 26:619-631. CrossRef Medline

Schneider CA, Rasband WS, Eliceiri KW (2012) NIH Image to ImageJ: 25 years of image analysis. Nat Methods 9:671-675. CrossRef Medline

Selvaraj S, Watt JA, Singh BB (2009) TRPC1 inhibits apoptotic cell degeneration induced by dopaminergic neurotoxin MPTP/MPP(+). Cell Calcium 46:209-218. CrossRef Medline

Selvaraj S, Sun Y, Singh BB (2010) TRPC channels and their implication in neurological diseases. CNS Neurol Disord Drug Targets 9:94-104. CrossRef Medline

Su Z, Zhou X, Haynes WJ, Loukin SH, Anishkin A, Saimi Y, Kung C (2007) Yeast gain-of-function mutations reveal structure-function relationships conserved among different subfamilies of transient receptor potential channels. Proc Natl Acad Sci U S A 104:19607-19612. CrossRef Medline Surmeier DJ, Guzman JN, Sanchez-Padilla J (2010) Calcium, cellular aging, and selective neuronal vulnerability in Parkinson's disease. Cell Calcium 47:175-182. CrossRef Medline

Tozzi A, Bengtson CP, Longone P, Carignani C, Fusco FR, Bernardi G, Mercuri NB (2003) Involvement of transient receptor potential-like channels in responses to mGluR-I activation in midbrain dopamine neurons. Eur J Neurosci 18:2133-2145. CrossRef Medline

Venkatachalam K, Montell C (2007) TRP channels. Annu Rev Biochem 76: 387-417. CrossRef Medline

Vennekens R, Menigoz A, Nilius B (2012) TRPs in the Brain. Rev Physiol Biochem Pharmacol 163:27-64. CrossRef Medline

Walker RG, Willingham AT, Zuker CS (2000) A Drosophila mechanosensory transduction channel. Science 287:2229-2234. CrossRef Medline

Wang D, Kennedy S, Conte D Jr, Kim JK, Gabel HW, Kamath RS, Mello CC, Ruvkun G (2005) Somatic misexpression of germline P granules and enhanced RNA interference in retinoblastoma pathway mutants. Nature 436:593-597. CrossRef Medline

Wu J, Shih HP, Vigont V, Hrdlicka L, Diggins L, Singh C, Mahoney M, Chesworth R, Shapiro G, Zimina O, Chen X, Wu Q, Glushankova L, Ahlijanian M, Koenig G, Mozhayeva GN, Kaznacheyeva E, Bezprozvanny I (2011) Neuronal store-operated calcium entry pathway as a novel therapeutic target for Huntington's disease treatment. Chem Biol 18:777793. CrossRef Medline

Xu K, Tavernarakis N, Driscoll M (2001) Necrotic cell death in C. elegans requires the function of calreticulin and regulators of $\mathrm{Ca}(2+)$ release from the endoplasmic reticulum. Neuron 31:957-971. CrossRef Medline

Yoon J, Ben-Ami HC, Hong YS, Park S, Strong LL, Bowman J, Geng C, Baek K, Minke B, Pak WL (2000) Novel mechanism of massive photoreceptor degeneration caused by mutations in the trp gene of Drosophila. J Neurosci 20:649-659. Medline

Zhao F, Li P, Chen SR, Louis CF, Fruen BR (2001) Dantrolene inhibition of ryanodine receptor $\mathrm{Ca} 2+$ release channels. Molecular mechanism and isoform selectivity. J Biol Chem 276:13810-13816. Medline

Zhou X, Su Z, Anishkin A, Haynes WJ, Friske EM, Loukin SH, Kung C, Saimi Y (2007) Yeast screens show aromatic residues at the end of the sixth helix anchor transient receptor potential channel gate. Proc Natl Acad Sci U S A 104:15555-15559. CrossRef Medline 